\title{
Double Root Anatomical Variations in a Single Patient: Endodontic Treatment and Rehabilitation of a Three-rooted First Premolar. Case Report
}

\author{
Variaciones Anatómicas de Raíces Dobles en un solo Paciente: Tratamiento Endodóntico \\ y Rehabilitación de un Primer Premolar Trirradicular. Reporte de Caso
}

\author{
Gonzalo H. Oporto V.*; Rubén Saavedra*; Camila C. Soto P.** \& Ramón Fuentes*
}

OPORTO, V. G. H.; SAAVEDRA, R.; SOTO, P. C. C. \& FUENTES, R. Double root anatomical variations in a single patient: endodontic treatment and rehabilitation of a three-rooted first premolar. Case report. Int. J. Morphol., 31(1):45-49, 2013.

SUMMARY: Abnormal interaction between oral epithelium and underlying mesenchematic tissue during odontogenesis could result in teeth with an anatomical variation. First maxilar premolar has such variable root canal morphology. However, (0.2-6\% of cases) a three-rooted premolar is particularly uncommon. First mandibular premolar frequently has one root and one single canal (75\% of cases), however, a tooth with two canals and two separate roots could be found (19.5-22.5\%). Execution of an accurate diagnosis of root canal system is essential to perform a successful endodontic treatment and tooth rehabilitation. This article describes diagnosis, endodontic treatment and rehabilitation (means single crown) of a maxillary three-rooted and three-canal first premolar, and a non-endodontically treated mandibular first premolar with two canals and two independent roots in a single patient.

KEY WORDS: Anatomical variation; Root canal; Teeth root; Teeth endodontically treated; Premolar; Crown.

\section{INTRODUCTION}

The tooth development results from a complicated interaction between oral epithelium and underlying mesenchematic tissue during odontogenesis (Fuentes \& Oporto 2009; Goh, 2001). In accordance to the period when this disturbance occurs, the tooth would show an anatomical variation and/or abnormal eruption.

Regarding main objectives of endodontic treatment are to debride root canals of pulp tissue remnants, disinfection and complete obturation of pulp Canal system means bio-compatible materials, knowledge of dental anatomy is one of the main factors to achieve successfully procedures into pulp canal system. Ignorance of normal morphology and possible anatomic variations of teeth, may lead to failure due to incorrect instrumentation and lack of instrumentation and three-dimensional obturation of the root canal system (Soares \& Leonardo, 2003; de Almeida-Gomes et al., 2006; Velmurugan et al., 2005; Holtzman, 1998; Shokohinejad, 2009; Barros et al., 2009; Poorni et al., 2010; D’Arcangelo et al., 2001). To minimize accidents and treatment failure, accurate radiographic examination with good-quality straight on and angled radiographic images are necessary for clinicians to distinguish root canal system and hence achieve with a correct diagnosis.

Normal morphology and anatomical variations of maxillary first premolars are relatively well documented. Usually have two roots $(61 \%)$ and either one $(35.5 \%)$ or three roots (3.5\%). The case of three-rooted and three-pulp canal is such a rare occurrence (0.2-6\%) (Soares \& Leonardo; Cleghorn et al., 2007; Oporto et al., 2010).

First Mandibular premolars usually have one root and one single canal in a $75 \%$ of cases (de Almeida-Gomes et al.; Poorni et al.; Oporto et al.). However, occurrence of two canals and two roots in a $19.5-22.5 \%$ of cases has been reported (de Almeida-Gomes et al.; Poorni et al.; Oporto et al.; Cleghorn et al.).

The aim of this paper is to report endodontic treatment and rehabilitation means single crown of a three-rooted and tree-pulp canal first maxillary premolar, and a non-

\footnotetext{
* Departamento de Odontología Integral Adultos, Facultad de Odontología, Universidad de La Frontera, Temuco, Chile.

** Ciclo de Destinación y Formación Cirujano Dentistas, Servicio de Salud Aysén, Coyhaique, Chile.
} 
endodontically treated mandibular first premolar with two canals and two independent roots. Both teeth were found in a single patient.

\section{CASE REPORT}

A 32 year old female patient without relevant medical records sought dental treatment at the Dental Clinic of the Chilean Red Cross, Temuco, Chile. Patient related a history of spontaneous pain in maxillary right area, in relation to premolars teeth. At dental evaluation time, no pain was related.

Clinical inspection revealed extensive dental caries lesion on mesial and occlusal surfaces of first right premolar (tooth 14), and lost of a coronal restoration on second right premolar (tooth 15). No swelling or sinus tract was detected. There was no response at palpation, percussion or termical test on second premolar, however, first premolar was sensitive to cold and hot, indicating tooth 14 had irreversible pulp damage.

Preoperative radiographs were taken. Radiographic evaluation of involved teeth indicated that caries on 14 was closer to pulp chamber. An abrupt lost of radiolucency at pulp canal floor was seen as well as an external increased diameter at this area. More apical was easily seen, with great definition, three roots and tree pulp canals (Fig. 1).

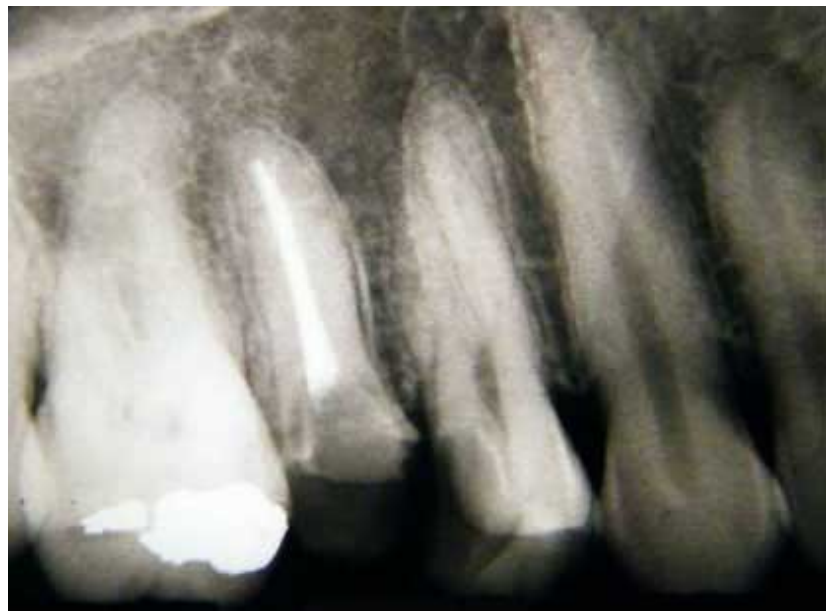

Fig. 1. Radiographic preoperative view of three rooted tooth 14 .

Radiographic evaluation of tooth 15 demonstrated complete crown destruction, a caries lesion inside root and a previous root canal treatment.

A similar lost of radiolucency at pulp canal floor, as seen as tooth 14, was observed at first mandibular premolar.
As well as 14 , more apically an anatomical variation was clearly observed, in this case, two roots and two pulp canals (Fig. 2). Clinical aspect of First mandibular premolar (tooth 34) crown did not show any indication to suspect presence of a root anomaly (Fig. 3). This tooth did not display any type of pathology.

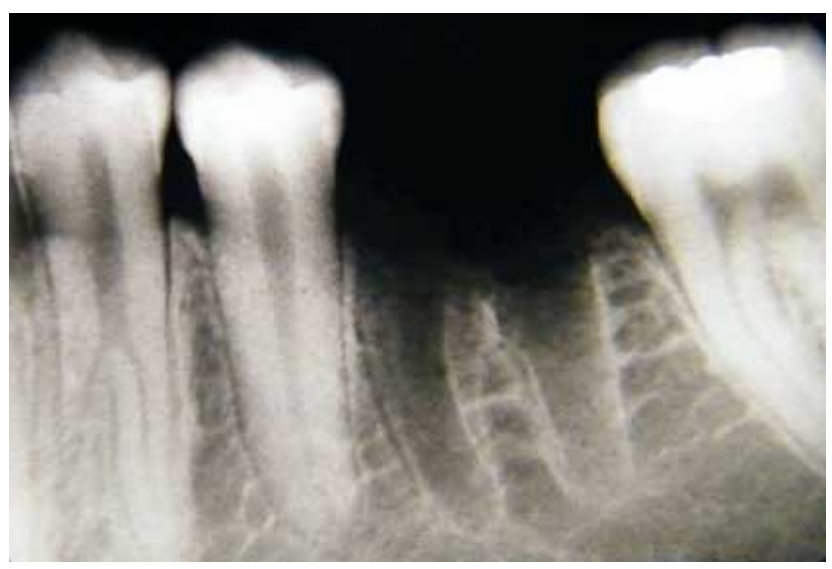

Fig. 2. Radiographic view of two separate roots and two canals at tooth 34 .

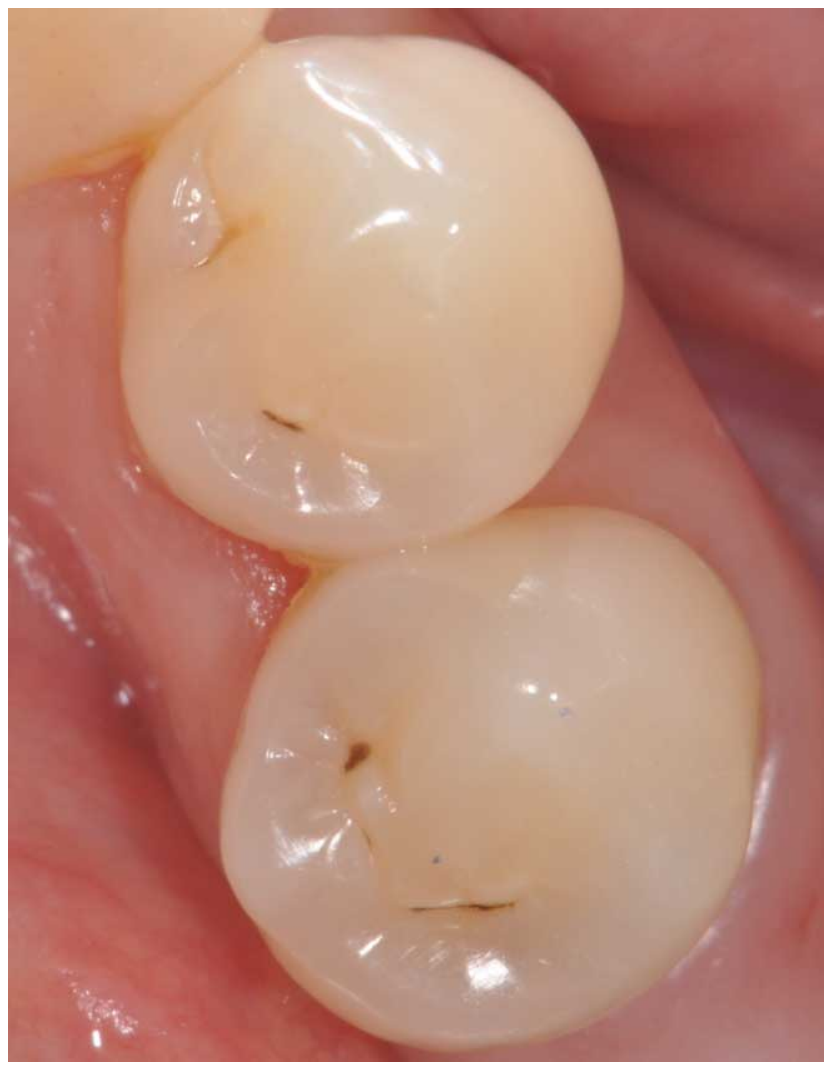

Fig. 3. Clinical crown view of tooth 34.

Based on this information, clinicians carry out a diagnosis and treatment plan, including perform a endodontic 
treatment and a single crown on 14, dental extraction on 15, placement of a dental implant and an implant-supported single crown at this tooth. Considering healthy conditions of 34 was no treatment executed.

To perform endodontic treatment on 14, the tooth was anesthetized using 2\% Lidocaine with 1:50000 Epinephrine (Anescart ${ }^{\circledR}$ Penta Farmacéutica, Santiago, Chile) and isolated using rubber dam. The pulp was accesed using a round diamond bur and an Endo-Z bur (Dentsply-Maillefer, Ballaigues, Switzerland) in a high-speed air motor handpiece. Considering coronal destruction at mesial area of crown, was not necessary (in this particular case) perform a T-Shaped outline cavity (Soares \& Leonardo). After removing the coronal pulp, the Canals were explored. Palatal and MesioBuccal with size 10 File and Disto-Buccal using size 0.6 File. Then, the root canals length was established; Palatal canal $21 \mathrm{~mm}$, mesio-buccal canal $22 \mathrm{~mm}$ and disto-buccal canal $20 \mathrm{~mm}$. A working length radiograph was taken, and the presence of three separate Canals, two buccals (one mesial and one distal) and one palatal were clinically confirmed (Fig. 4).

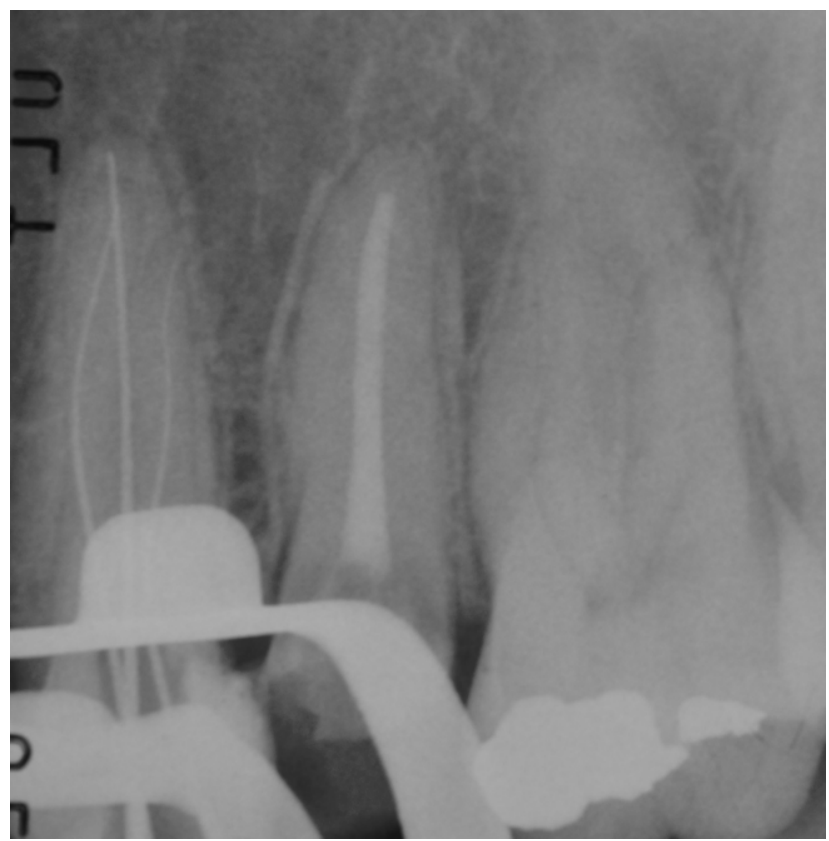

Fig. 4. Working length radiograph of tooth 14. Confirmed three separate roots and canals.

The root Canals were routinely instrumented. Palatal canal to a size $40 \mathrm{~K}$-File; mesio-buccal to a size $35 \mathrm{~K}$-File and disto-buccal to a 20 size K-File (Dentsply-Maillefer, Ballaigues, Switzerland). During treatment, the pulp chamber was frequently flushed with $5 \%$ sodium hypochlorite to remove debris and bacteria.
Calcium hydroxide was used as an inter-visit medication to increase the predictability of treatment in case to persist an undetected area of root canal system (Holtzman; Frank, 1979; Bystrom et al., 1985).

Once tooth was symptom free, the three canals were obturated with laterally condensed gutta-percha and Grossman sealer.

Then tooth rehabilitation by means a single unit metal ceramic crown was performed. A metal post (Unimetric, Dentsply-Maillefer, Ballaigues, Switzerland) was placed on palatal canal. Later, tooth was prepared by conventional manner, with the aim to obtaining a convergence of $6^{\circ}$ between walls. Margins were prepared with champfer at gingival level (Fig. 5).

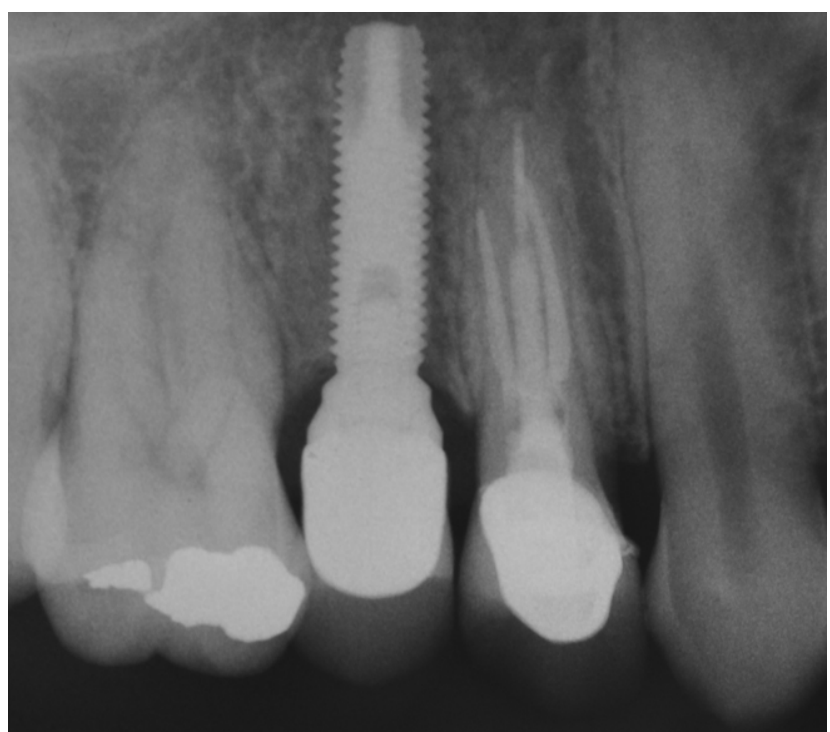

Fig. 5. Radiographic control of endodontic treatment and single crown.

\section{DISCUSSION}

To practitioners of endodontic and prosthodontics, knowledge of normal anatomy and anatomical variations is transcendental to perform a successful procedure into pulp canal system such as endodontic treatment or post positioning. Normal morphology and anatomical variations of tooth are extensively documented in literature, actually, has been reported racial differences in canal morphology (Atieh, 2008; Chaparro et al., 1999). In all cases, is highlighted that a three rooted premolar with three pulp canals is a very rare occurrence, reported in a $0.2-6 \%$ of cases (Soares \& Leonardo; Cleghorn et al.; Oporto et al.). First mandibular premolar with two canals and two separate 
roots is also an infrequent anatomical configuration, observed in a 19.5-22.5\% of cases (de Almeida-Gomes et al.; Poorni et al.; Oporto et al.; Cleghorn et al.).

Normal anatomy as well as anatomical variations must be considered at the beginning of treatment. At this point, accurate preoperative radiographs (straight and angled) are essential giving indications to clinicians as to the number of roots and canals that exist in a tooth (Soares \& Leonardo; de Almeida-Gomes et al.; Velmurugan et al.; Holtzman; Shokohinejad; Barros et al.; Poorni et al.; D'Arcangelo et al.). Is important considering that, once obtained a good quality radiographic images, only an accurate analysis of imagenologic studies leads to obtain a correct diagnosis of root and pulp canal morphology.

Despite previously mentioned, radiographic images and radiographic analysis themselves, are not always enough data in order to obtain a suitable abstraction of root and pulp canal system. Adequate examination of pulp chamber floor may give to clinician more extensive information about number, type and position of pulp canal system means observation of pulp canal orifices and wall anatomy (Poorni et al.).

Previous reports of multi-rooted premolars indicates that crown of this teeth frequently exhibit a greater dimension mesio-distal than normal ones (Barros et al.). Considering extensive crown destruction of tooth 14, it was impossible obtain that information, however, in case of tooth 34, it dimension was not different to second mandibular premolar. Additional information will be highly valuable in this field to know if really an increased coronary dimension is directly related with a root shape or number alteration.
To perform an endodontic treatment in a tooth with anatomical variations (confirmed or suspected) must be considering several points. There are two to highlight. Soares \& Leonardo states that, considering maxillary first and second premolars frequently show buccal orifices closer to each other, a cut must be done during preparation at the buccal-proximo angle from entrance of buccal canals to the cavo-surface angle (Balleri et al., 1997) creates an appropriated outline access. Holtzman recommends use Calcium Hidroxide as an inter-visit intra-canal medication to increase predictability of treatment in case inaccessible or undetected parts of root canal system (Frank, 1979; Bystrom et al.).

The presence of two teeth with similar root and canals anatomical variations is remarkable in a single patient. It has been reported that this type of anatomical variations should be influenced by an inheritance pattern, considering root anatomical variations has been seen in sibling patients (Barros et al.). Thus, other teeth anomalies (Dens evaginatus) were reported in several members of a family (Stewart et al., 1972). Further research must be developed to obtain additional information about that presumption of genetic component in teeth anatomical variations is effective.

Shape and configuration of root canal system is always variable. Clinicians must handle advanced knowledge of pulp canal morphology, frequency of appearance of anatomical variations and how to identify it. Routinely accurate radiographic and clinical analysis must be done previously to begin any procedure into pulp canal system. Performance of an endodontic treatment is always going to be a unique experience.

OPORTO, V. G. H.; SAAVEDRA, R.; SOTO, P. C. C. \& FUENTES, R. Variaciones anatómicas de raíces dobles en un solo paciente: tratamiento endodóntico y rehabilitación de un primer premolar trirradicular. Reporte de caso. Int. J. Morphol., 31(1):45-49, 2013.

RESUMEN: La interacción anormal entre el epitelio oral y el tejido mesenquimático subyacente durante la odontogénesis puede resultar en la formación de un diente con una variación anatómica. El primer premolar maxilar posee una anatomía relativamente variable, sin embargo, es especialmente poco frecuente $(0,2 \%$ a $6 \%$ de los casos) la presencia de este diente con tres raíces y tres canales radiculares. El primer premolar mandibular posee frecuentemente una raíz y un canal radicular (75\% de los casos) y es bastante más infrecuente encontrar este diente con dos raíces y dos canales radiculares (19.5 a 22.5\%). Un diagnóstico acabado y preciso de es fundamental para lograr un exitoso tratamiento de endodoncia y posterior rehabilitación. Este artículo describe el diagnóstico, tratamiento de endodoncia y rehabilitación (mediante prótesis fija singular) de un primer premolar maxilar con tres raíces y tres canales radiculares, además el reporte de un caso de un primer premolar mandibular biradicular con dos canales radiculares. Ambos se presentan en un mismo paciente.

PALABRAS CLAVE: Variación anatómica; Canal radicular; Raíz dentaria; Diente endodonticamente tratado; Premolar; Corona. 


\section{REFERENCES}

Atieh, M. A. Root and canal morphology of maxillary first premolars in a Saudi population. J. Contemp. Dent. Pract., 9(1):46-53, 2008.

Balleri, P.; Gesi, A. \& Ferrari, M. Primer premolar superior com tres raíces. Endod. Pract., 3:13-5, 1997.

Barros, D. B.; Guerreiro Tanomaru, J. M. \& Tanomaru-Filho, M. Root canal treatment of three-rooted maxillary second premolars: report of four cases. Aust. Endod. J., 35(2):73-7, 2009.

Bystrom, A.; Claesson, R. \& Sundqvist, G. The antibacterial effect of camphorated paramonochlorophenol, camphorated phenol and calcium hydroxide in the treatment of infected root canals. Endod. Dent. Traumatol., 1(5):170-5, 1985.

Chaparro, A. J.; Segura, J. J.; Guerrero, E.; Jiménez-Rubio, A.; Murillo, C. \& Feito, J. J. Number of roots and canals in maxillary first premolars: study of an Andalusian population. Endod. Dent. Traumatol., 15(2):65-7, 1999.

Cleghorn, B. M.; Christie, W. H. \& Dong, C. C. The root and root canal morphology of the human mandibular first premolar: a literature review. J. Endod., 33(5):509-16, 2007. EN TEXTO Blaine

de Almeida-Gomes, F.; de Sousa, B. C. \& dos Santos, R. A. Unusual anatomy of mandibular premolars. Aust. Endod. J., 32(1):43$5,2006$.

D'Arcangelo, C.; Varvara, G. \& De Fazio, P. Root canal treatment in mandibular canines with two roots: a report of two cases. Int. Endod. J., 34(4):331-4, 2001.

Frank, A. L. Calcium hydroxide: the ultimate medicament? Dent. Clin. North Am., 23(4):691-703, 1979.

Fuentes, R. \& Oporto, G. Tercer molar ectópico impactado en zona retromolar. Reporte de caso. Int. J. Morphol., 27(1):35-8, 2009.

Goh, Y. H. Ectopic eruption of maxillary molar tooth--an unusual cause of recurrent sinusitis. Singapore Med. J., 42(2):80-1, 2001.

Holtzman, L. Root canal treatment of mandibular second premolar with four root canals: a case report. Int. Endod. J., 31(5):364$6,1998$.

Oporto, G.; Fuentes, R. \& Soto, C. Variaciones anatómicas radiculares y sistemas de canales. Int. J. Morphol., 28(3):94550,2010

Poorni, S.; Karumaran, C. S. \& Indira, R. Mandibular first premolar with two roots and three canals. Aust. Endod. J., 36(1):32-4,
2010.

Shokouhinejad, N. Root canal re-treatment of a mandibular second premolar with three root canals: a case report. Aust. Endod. J., 35(3):180-2, 2009.

Soares, J. A. \& Leonardo, R. T. Root canal treatment of threerooted maxillary first and second premolars--a case report. Int. Endod. J., 36(10):705-10, 2003.

Stewart, R. E.; Dixon, G. H. \& Graber, R. B. Dens evaginatus (tuberculated cusps): genetic and treatment considerations. Oral Surg. Oral Med. Oral Pathol., 46(6):831-6, 1978.

Velmurugan, N.; Parameswaran, A.; Kandaswamy, D.; Smitha, A.; Vijayalakshmi, D. \& Sowmya, N. Maxillary second premolar with three roots and three separate root canals--case reports. Aust. Endod. J., 31(2):73-5, 2005.

Correspondence to:

Gonzalo H. Oporto V.

Departamento de Odontología Integral Adultos

Facultad de Odontología

Universidad de La Frontera

Manuel Montt $112,4^{\circ}$ piso

Temuco

CHILE

Phone: $56-45-325775$

Email: gonzalo.oporto@ufrontera.cl

Received: 03-09-2012

Accepted: 10-12-2012 